\title{
Power Control of Doubly Fed Induction Machine using a Rotor Side Matrix Converter
}

Kenneth Spiteri, Cyril Spiteri Staines, Maurice Apap

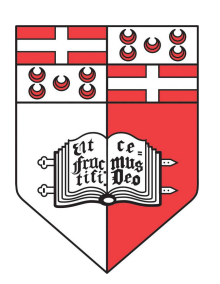

UNIVERSITY OF MALTA

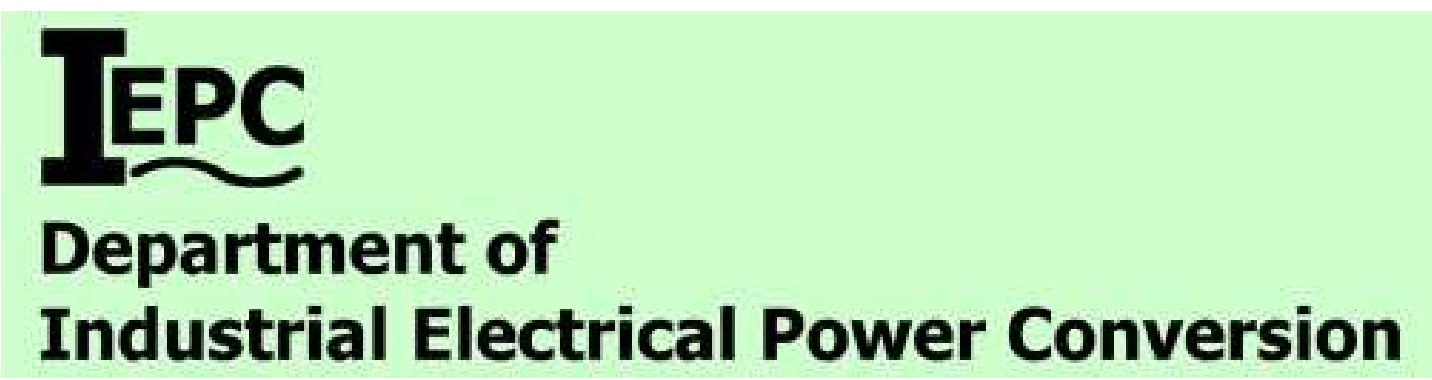




\section{Presentation Outline IEPC}

$>$ Wind Grid-Connected Systems

$>$ Doubly Fed Induction Machine

$>$ Matrix Converter and Experimental Rig

$>$ Results 


\section{Wind Grid-Connected Systems}

\section{Overview of}

\section{Wind Grid-Connected Systems}




\section{Wind Grid-Connected Systems}

\section{Fixed Speed direct on line generator}

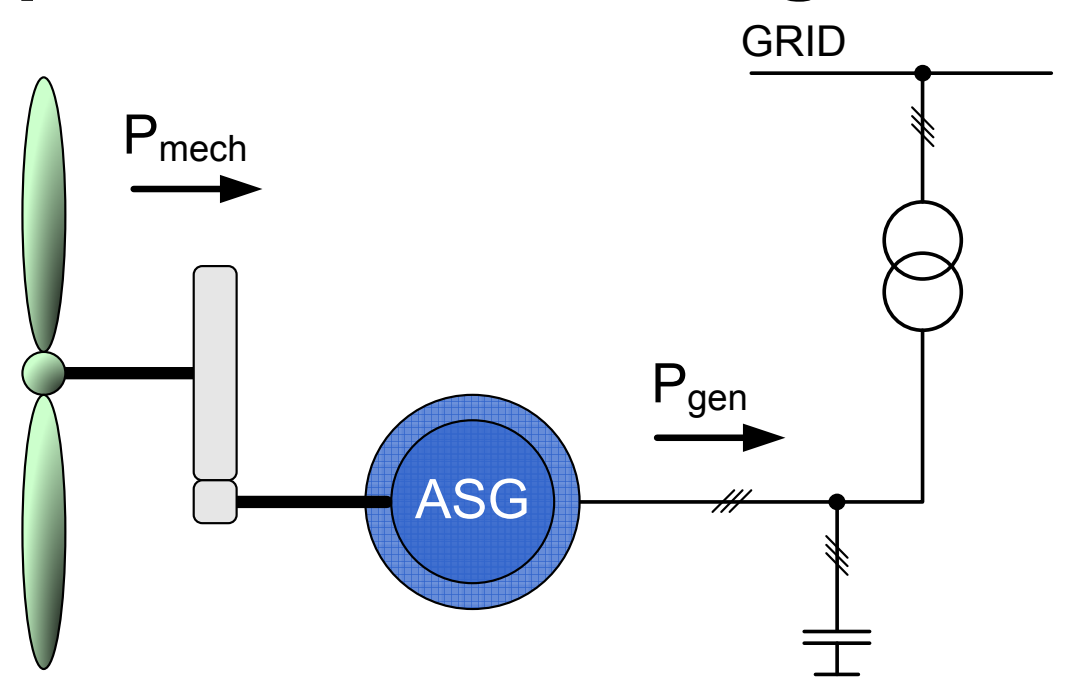

- $\quad$ Direct on line. No expensive power electronics converter needed.

- Mechanical control (complex \& expensive)

- Blades pitch angle Control.

$>$ Maximum power point tracking not possible.

- Hydro-Dynamically controlled gearbox.

$>$ Continuously controllable variable gear box ratio.

$>$ Maximum power point tracking possible. 


\section{Wind Grid-Connected Systems}

\section{Adjustable Speed Using Synchronous Generator}

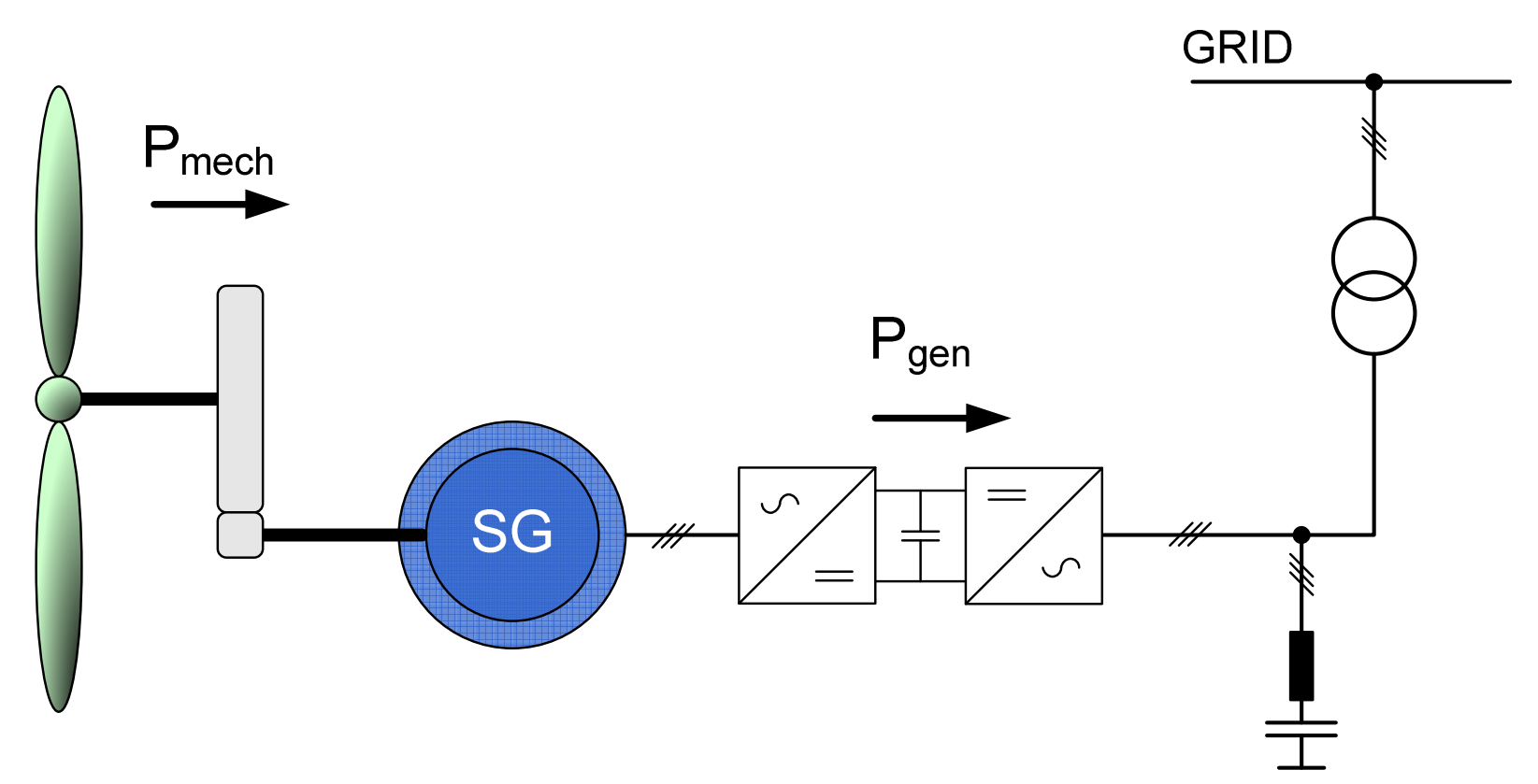

- Mechanical control system is kept simple, hence less expensive.

- Adjustable Speed Drive allows for Maximum Power Operation.

- Generator produces variable-frequency AC power.

- A power electronics converter is needed.

$>$ Power converter has to be rated $100 \%$ of total system VA. 


\section{Wind Grid-Connected Systems}

UNIVERSITY

OF MALTA

\section{Adjustable Speed Using Doubly Fed Induction Generator}

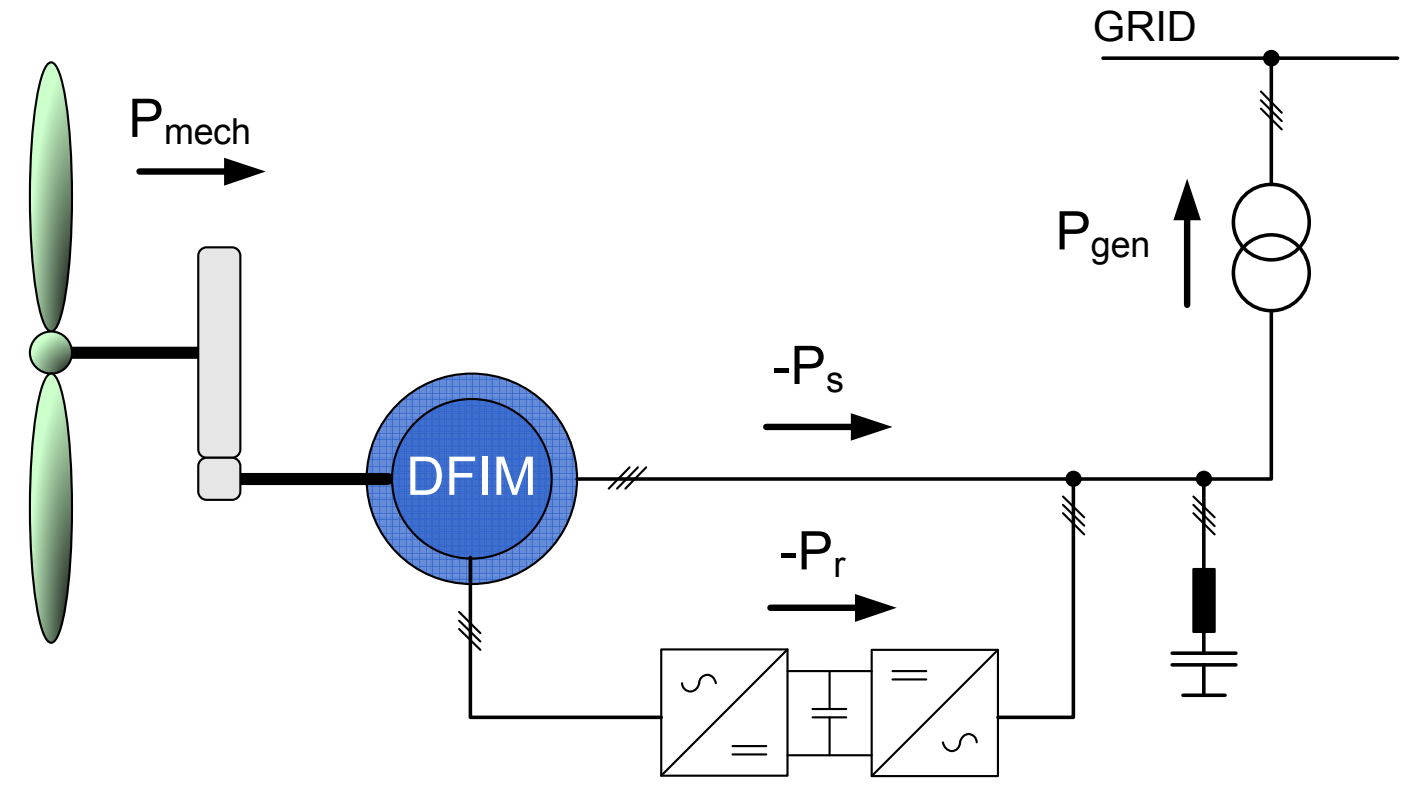

- Mechanical control system is kept simple, hence less expensive.

- Adjustable Speed Drive allows for Maximum Power Operation.

- Generator produces fixed-frequency fixed-voltage AC power.

- A power electronic converter is only needed to supply the slip power.

$>$ Power converter typically rated $25 \%$ of total system VA (less expensive). 


\section{Doubly Fed Induction Machine IEPC}

\section{Vector Control of the Doubly Fed Induction Machine}




\section{DFIM Steady-State Model}

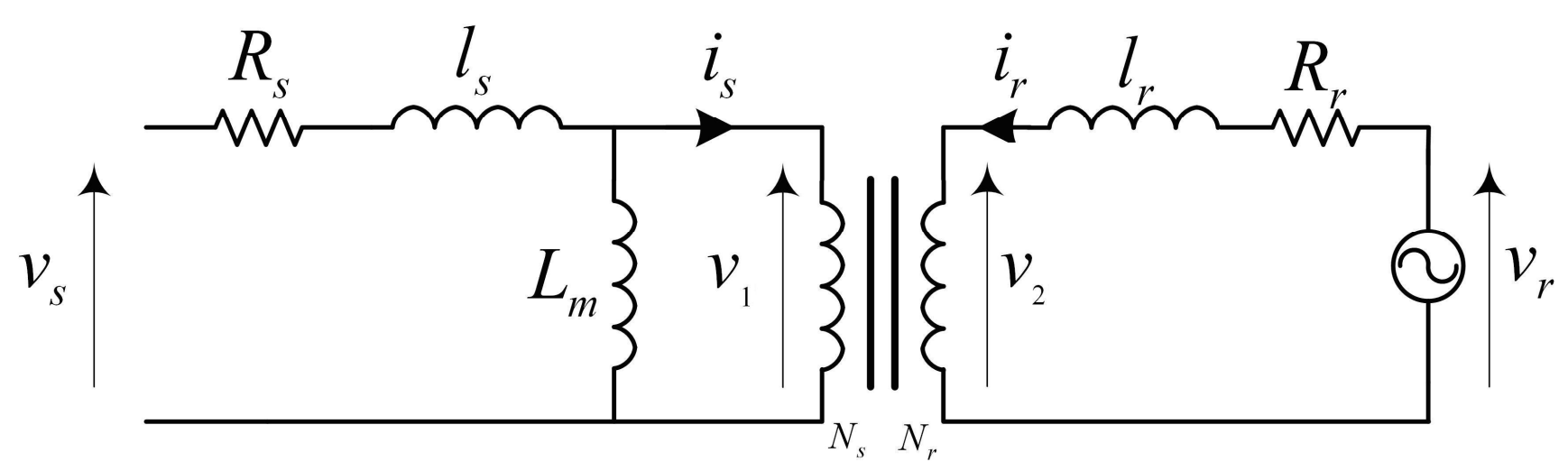

Power transferred through air-gap from stator:

$$
P_{s}=3 v_{1} i_{s}^{*}
$$
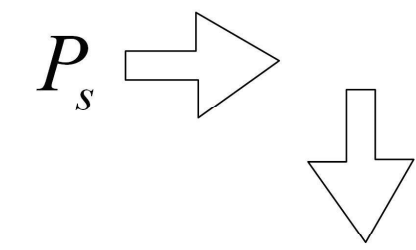

$\measuredangle P_{r}$

Power transferred through air-gap from rotor:

$P_{\text {mech }}$

$$
P_{r}=3 v_{2} i_{r}^{*}
$$

Mechanical Power developed is:$$
P_{r}=3\left(\frac{v_{1} s}{N_{s r}}\right)\left(-i_{s}^{*} N_{s r}\right)
$$

$$
\begin{aligned}
& P_{\text {mech }}=P_{s}+P_{r} \\
& P_{\text {mech }}=P_{s}-s P_{s}=P_{s}(1-s)
\end{aligned}
$$$$
P_{r}=-3 v_{1} i_{s}^{*} s
$$$$
P_{r}=-s P_{s}
$$ 


\section{Power Flow in a DFIM}

UNIVERSITY

OF MALTA

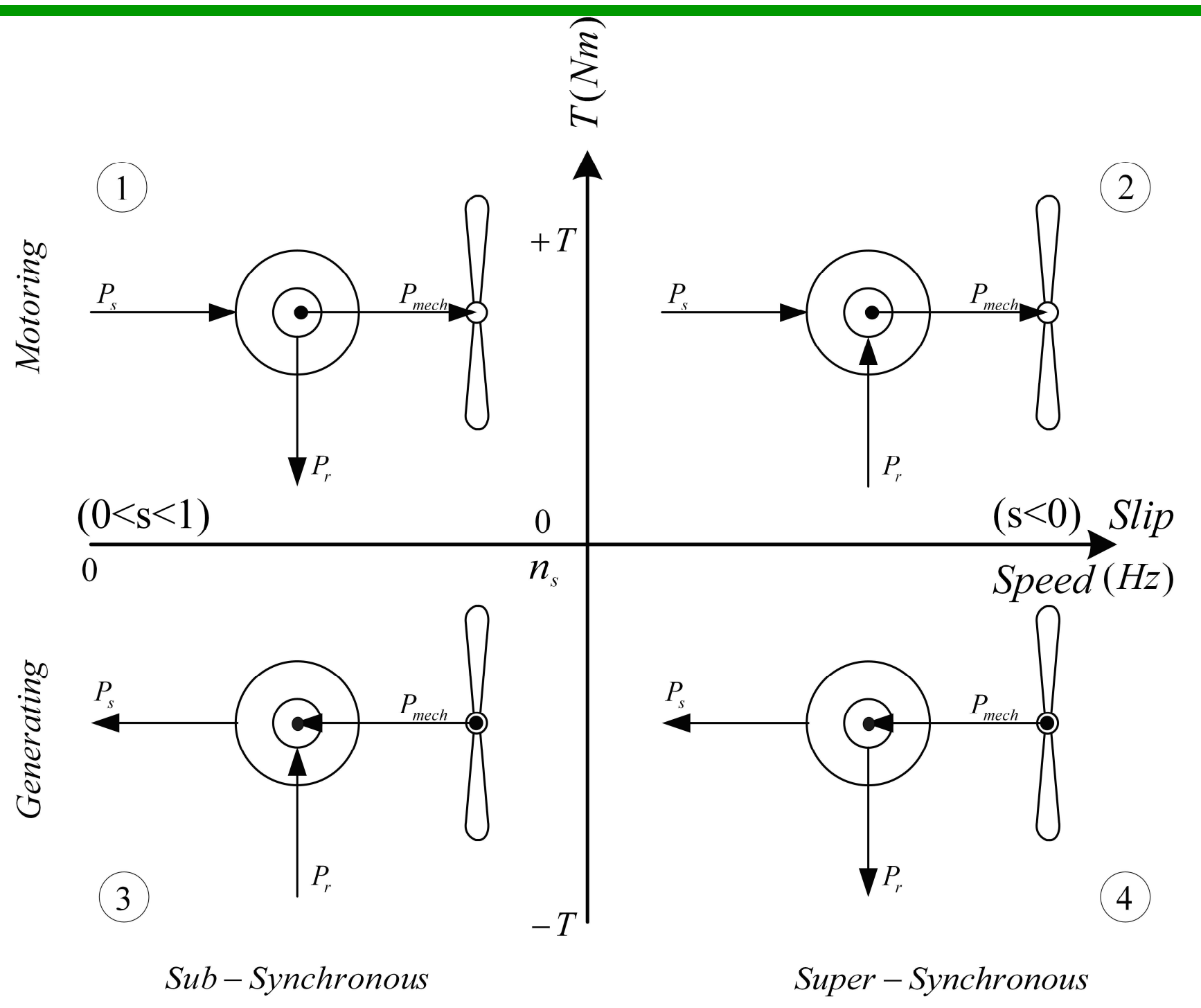




\section{DFIM dynamic model}

UNIVERSITY

OF MALTA

DFIM Modelling in stator and rotor frames:

$$
v_{S_{\alpha \beta}}=R_{S} i_{S_{\alpha \beta}}+\frac{d\left(\Psi_{S_{\alpha \beta}}\right)}{d t} \quad v_{R_{\alpha \beta \beta}}=R_{R} i_{R_{\alpha \beta \beta^{\prime}}}+\frac{d\left(\Psi_{R_{\alpha \beta \beta}}\right)}{d t}
$$

DFIM Modelling in rotating dq frame:

$$
v_{S_{d q}}=R_{S} i_{S_{d q}}+\frac{d\left(\Psi_{S_{d q}}\right)}{d t}+j \omega_{e} \Psi_{S_{d q}} \quad v_{R_{d q}}=R_{R} i_{R_{d q}}+\frac{d\left(\Psi_{R_{d q}}\right)}{d t}+j \omega_{s l} \Psi_{R_{d q}}
$$

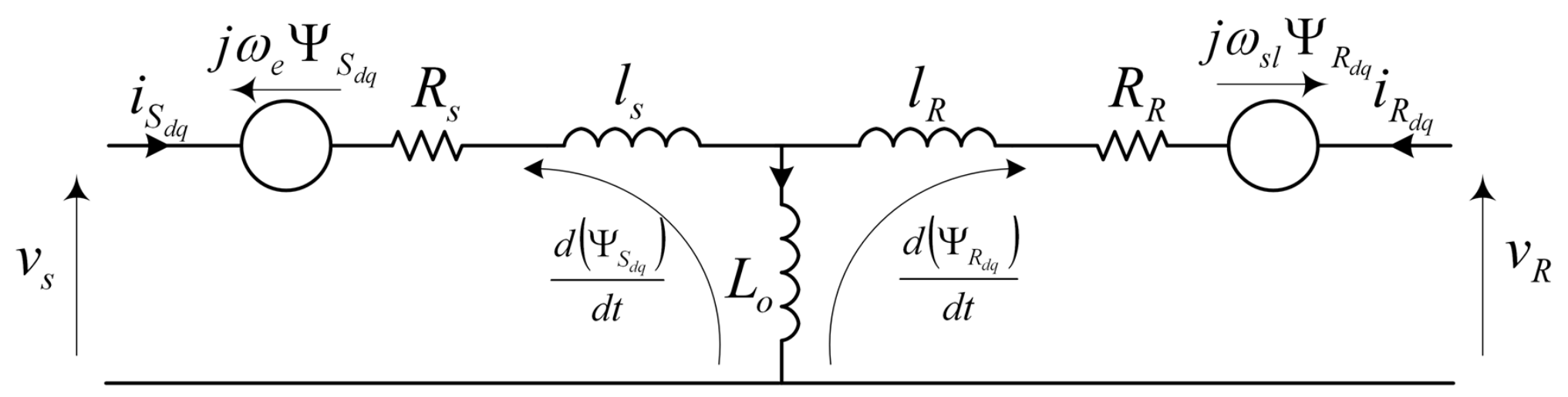




\section{DFIM Stator Field Orientated Vector Control}

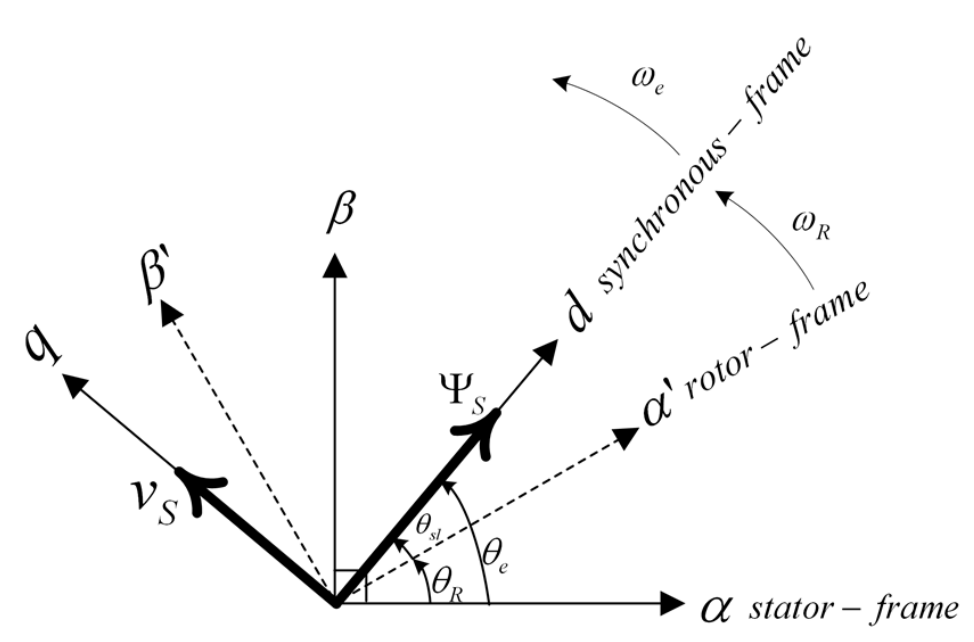

- Aligning the synchronous frame to the stator $\Psi_{S}$, leads to:

$$
\Psi_{S_{d}}=\Psi_{S} \quad \Psi_{S_{q}}=0
$$

- Neglecting stator resistance and assuming steady state grid supply the stator flux vector becomes constant in the dq frame and the stator dynamic equations may be written as:

$$
v_{S_{d}}=-\omega_{e} \Psi_{S_{q}}=0 \quad v_{S q}=\omega_{e} \Psi_{S_{d}}
$$




\section{DFIM SFO Vector Control Rotor Dynamic Equations}

Using the flux relationships:

$$
\begin{aligned}
& \Psi_{S}=L_{S} i_{S}+L_{O} i_{R} \\
& \Psi_{R}=L_{R} i_{R}+L_{O} i_{S}
\end{aligned}
$$

the rotor dynamic equations may be arranged in terms of $\Psi_{S}$ and $i_{R}$

$$
\begin{aligned}
& v_{R_{d}}=\underbrace{R_{R} i_{R_{d}}+\delta L_{R} \frac{d\left(i_{R_{d}}\right)}{d t}}_{\text {Linear }} \underbrace{-\delta L_{R} \omega_{s l} i_{R_{q}}}_{\text {Coupling }} \\
& v_{R_{q}}=\underbrace{R_{R} i_{R_{q}}+\delta L_{r} \frac{d\left(i_{R_{q}}\right)}{d t}}_{\text {Linear }} \underbrace{\omega_{s l}\left(\delta L_{R} i_{R_{d}}+\frac{L_{O}}{L_{S}} \Psi_{S_{d}}\right)}_{\text {Coupling }}
\end{aligned}
$$

These equations can be used for PI current control design for SFO vector control. 


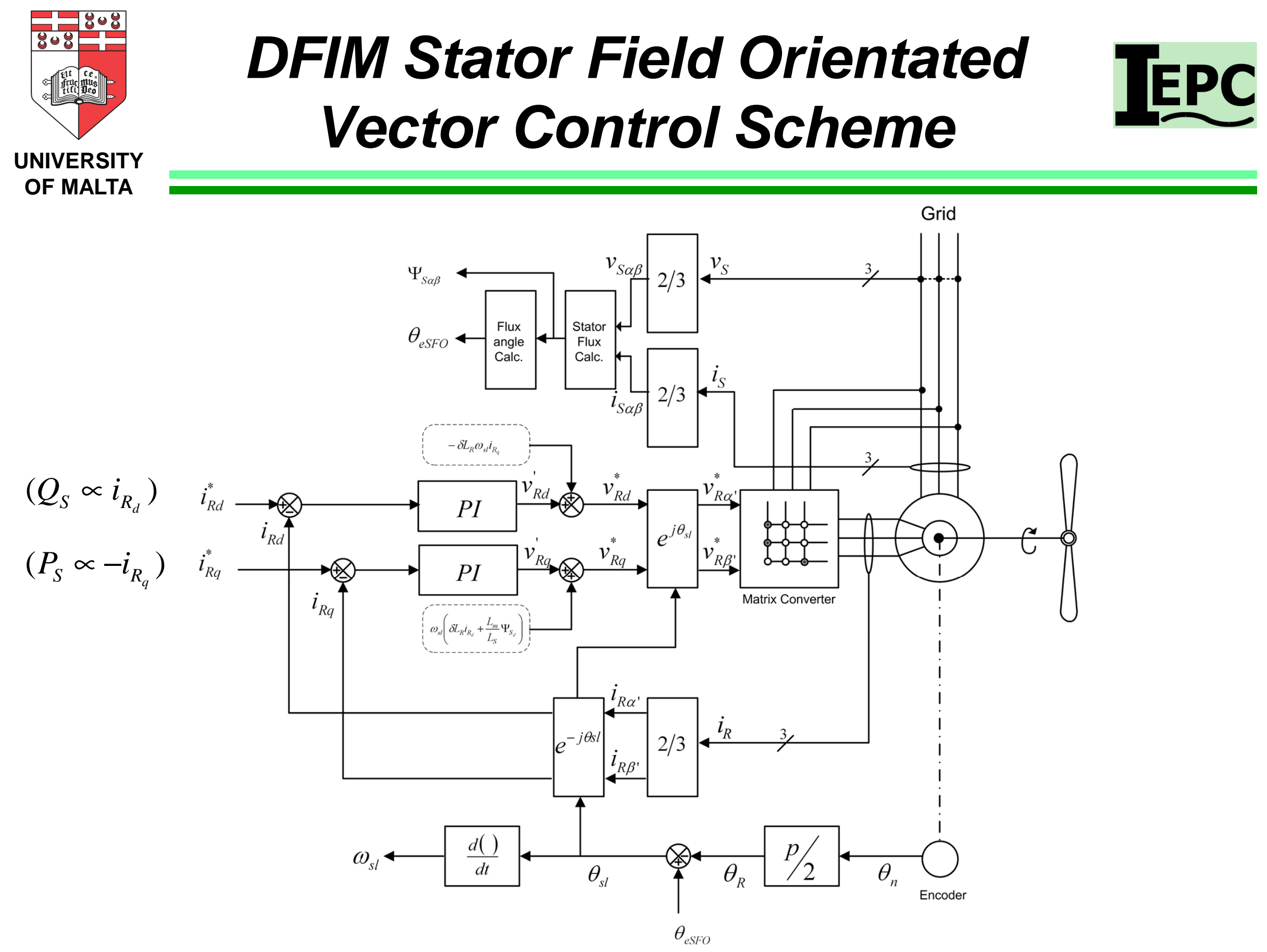




\section{DFIM Indirect Stator Power Control}

- The stator active power is defined as: $\quad P_{S}=3 \operatorname{Re}\left(v_{S} i_{S}^{*}\right)$

- whereas the reactive power is defined as: $Q_{S}=3 \operatorname{Im}\left(v_{S} i_{S}^{*}\right)$

- It can be shown after some mathematical manipulation that:

$$
\begin{array}{ll}
P_{S}=-3 \frac{L_{O}}{L_{S}} i_{R_{q}} \Psi_{S} \omega_{e} & \left(P_{S} \propto-i_{R_{q}}\right) \\
Q_{S}=-3\left(\frac{\Psi_{S} v_{S}}{L_{S}}-\frac{L_{O} v_{S}}{L_{S}} i_{R_{d}}\right) & \left(Q_{S} \propto i_{R_{d}}\right)
\end{array}
$$




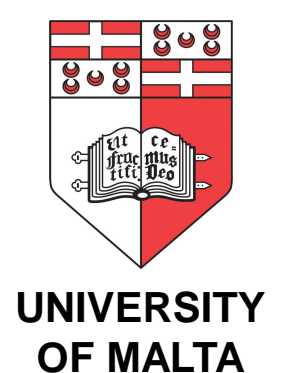

\section{Matrix Converter and Hardware Setup}

The Matrix Converter and the DFIM Test Rig 


\section{Matrix Converter Circuit}

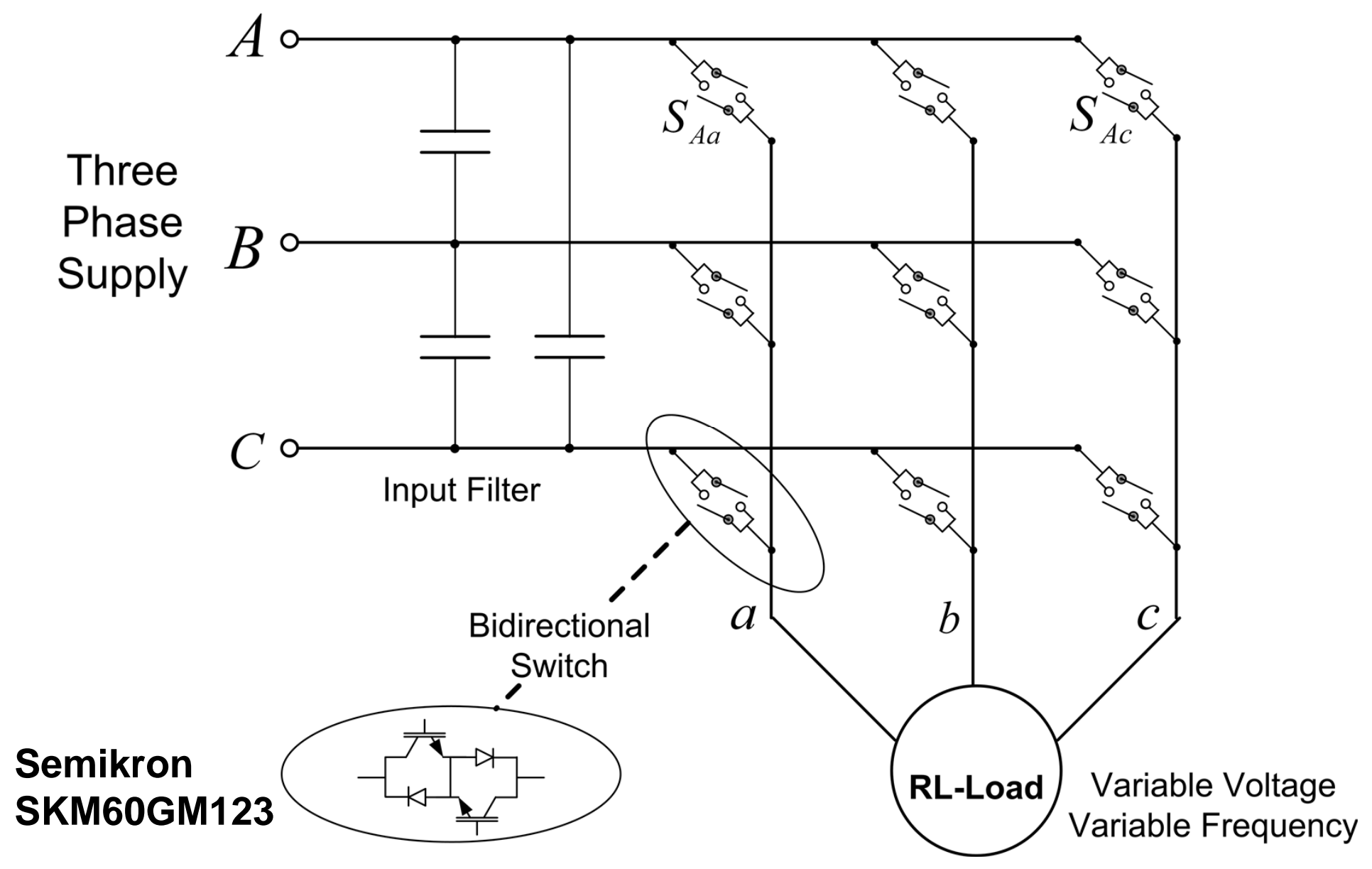




\section{Matrix Converter Properties}

- Each output phase can be connected to any input phase at any time

- Direct Conversion (no power storage elements)

- Power In = Power Out at all times

- Bidirectional power flow due to bidirectional switches

- Sinusoidal input currents due to PWM control and input filter

- Input power factor can be set as desired - this includes operation at $\mathrm{PF}=1$ 


\section{5kW Matrix Converter Circuit IEPC}

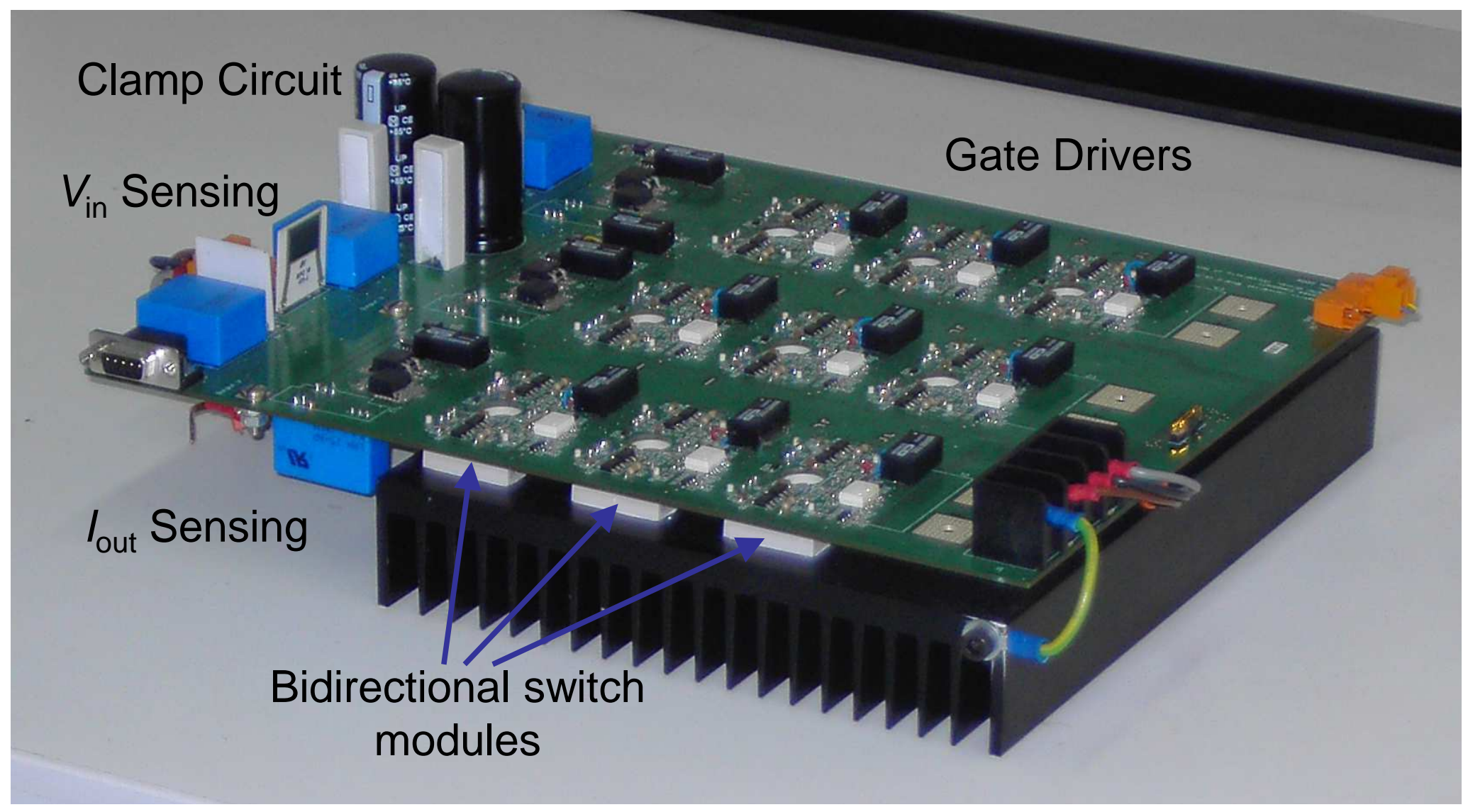




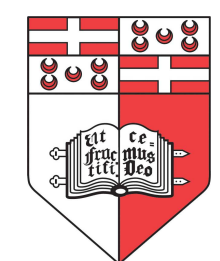

\section{Experimental Setup}

IEPC

UNIVERSITY

OF MALTA

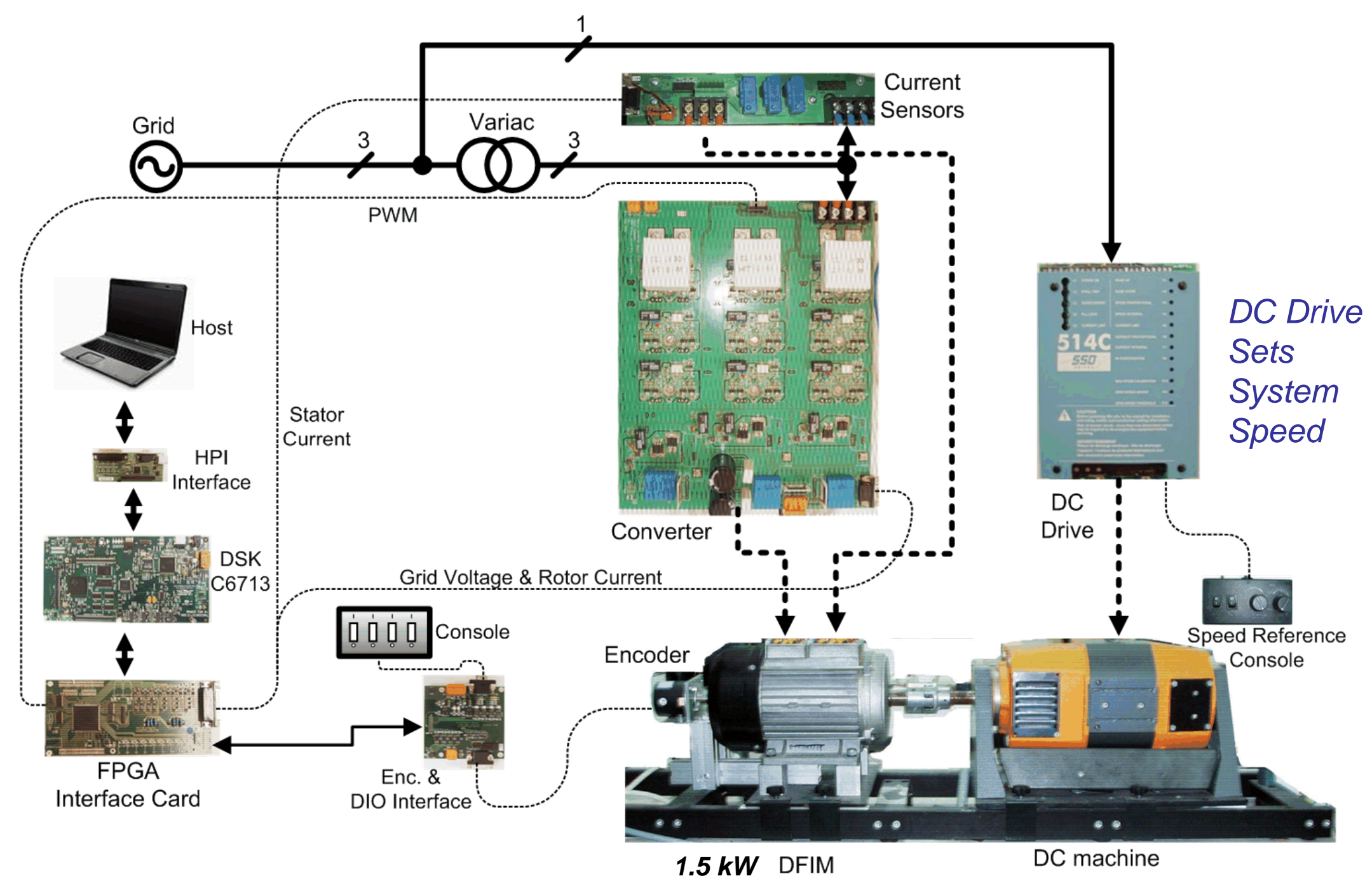




\section{Experimental Results}

\section{Experimental Results}




\section{DFIM Stator Power Control}

Stator Active and Reactive Power for step in $i_{R_{q}}$

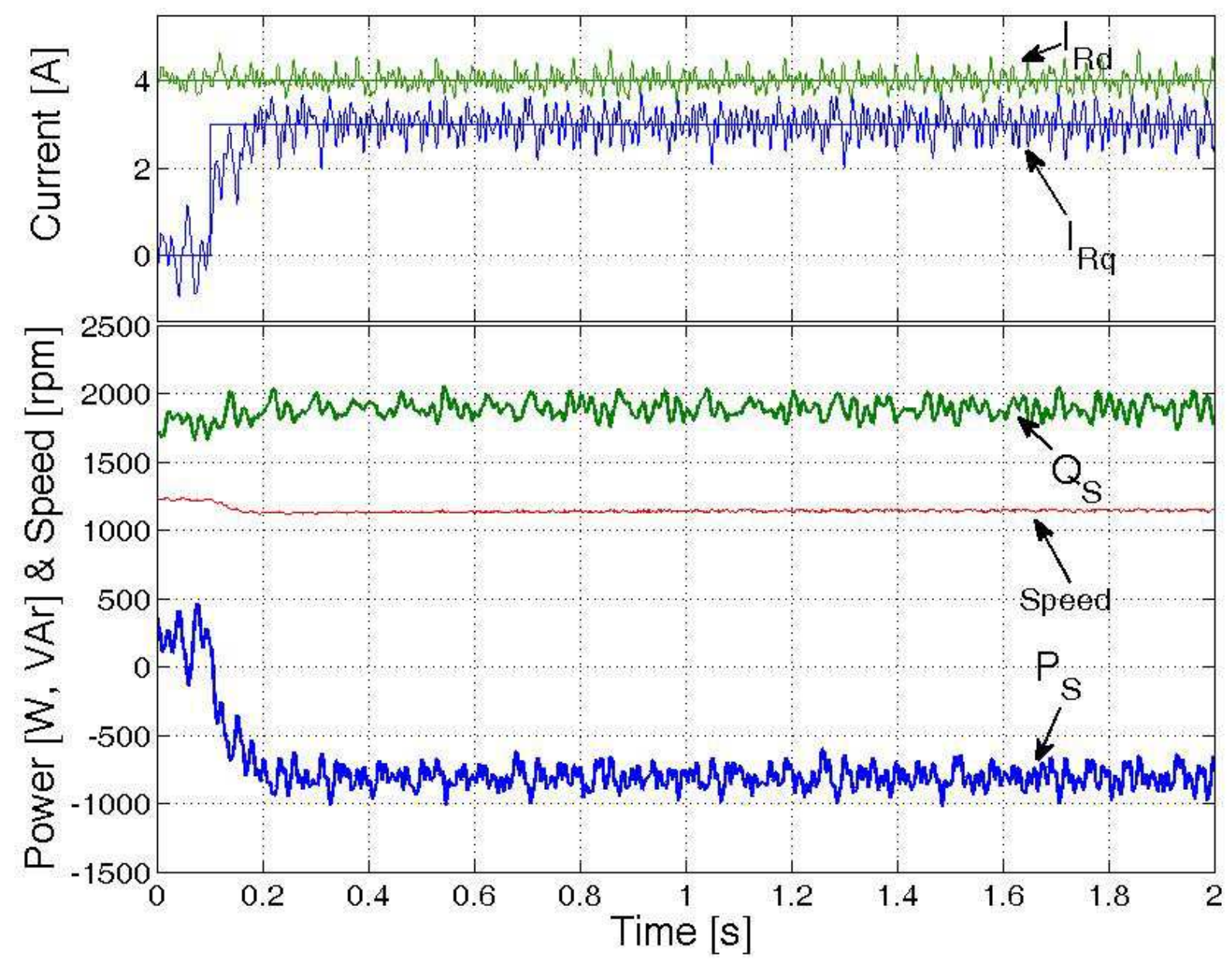




\section{DFIM Stator Power Control}

UNIVERSITY

OF MALTA

Stator Active and Reactive Power for step in $i_{R_{d}}$

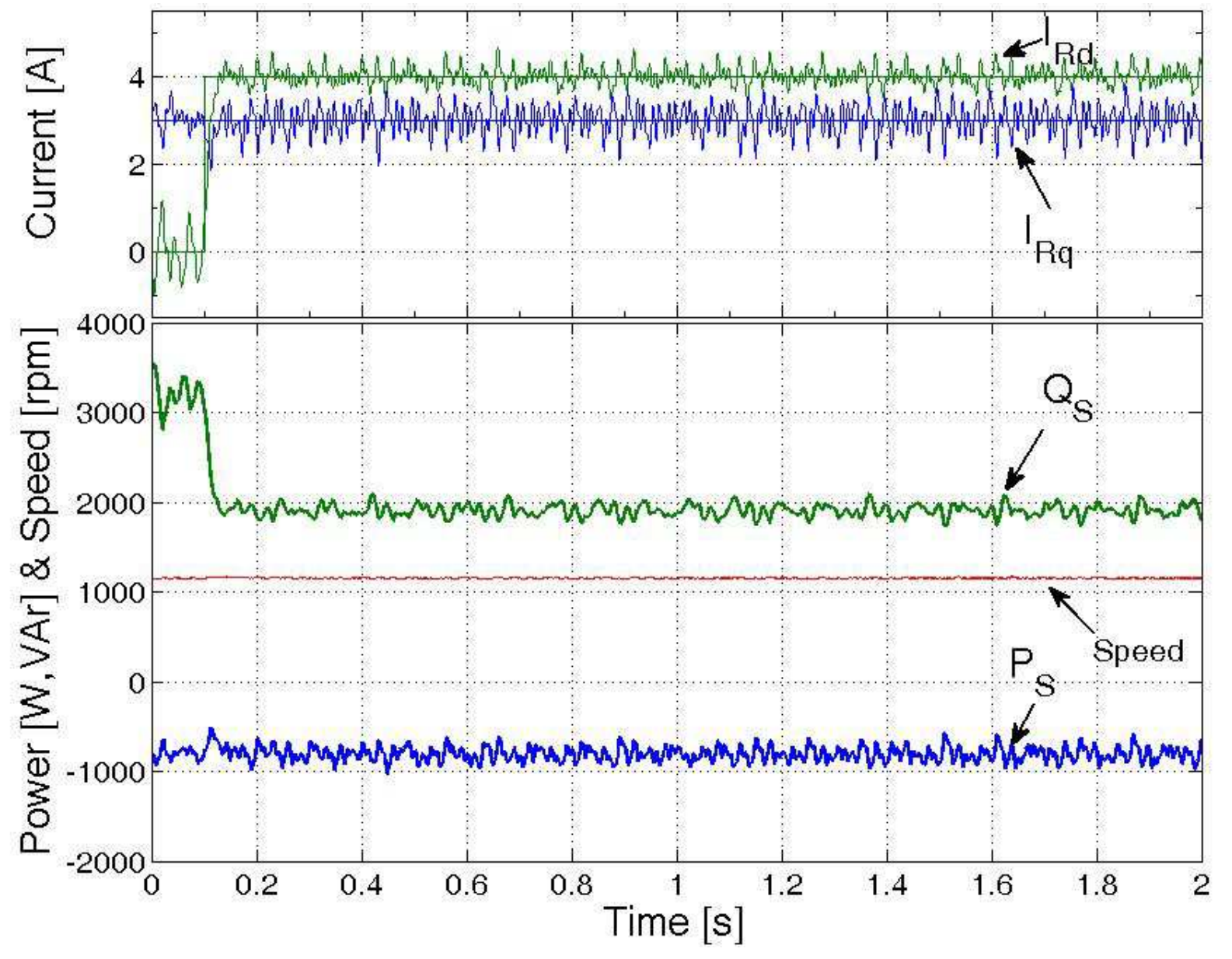




\section{Variable Speed Operation}

Operation Through Synchronous Speed: Automatic Rotor Current Reversal

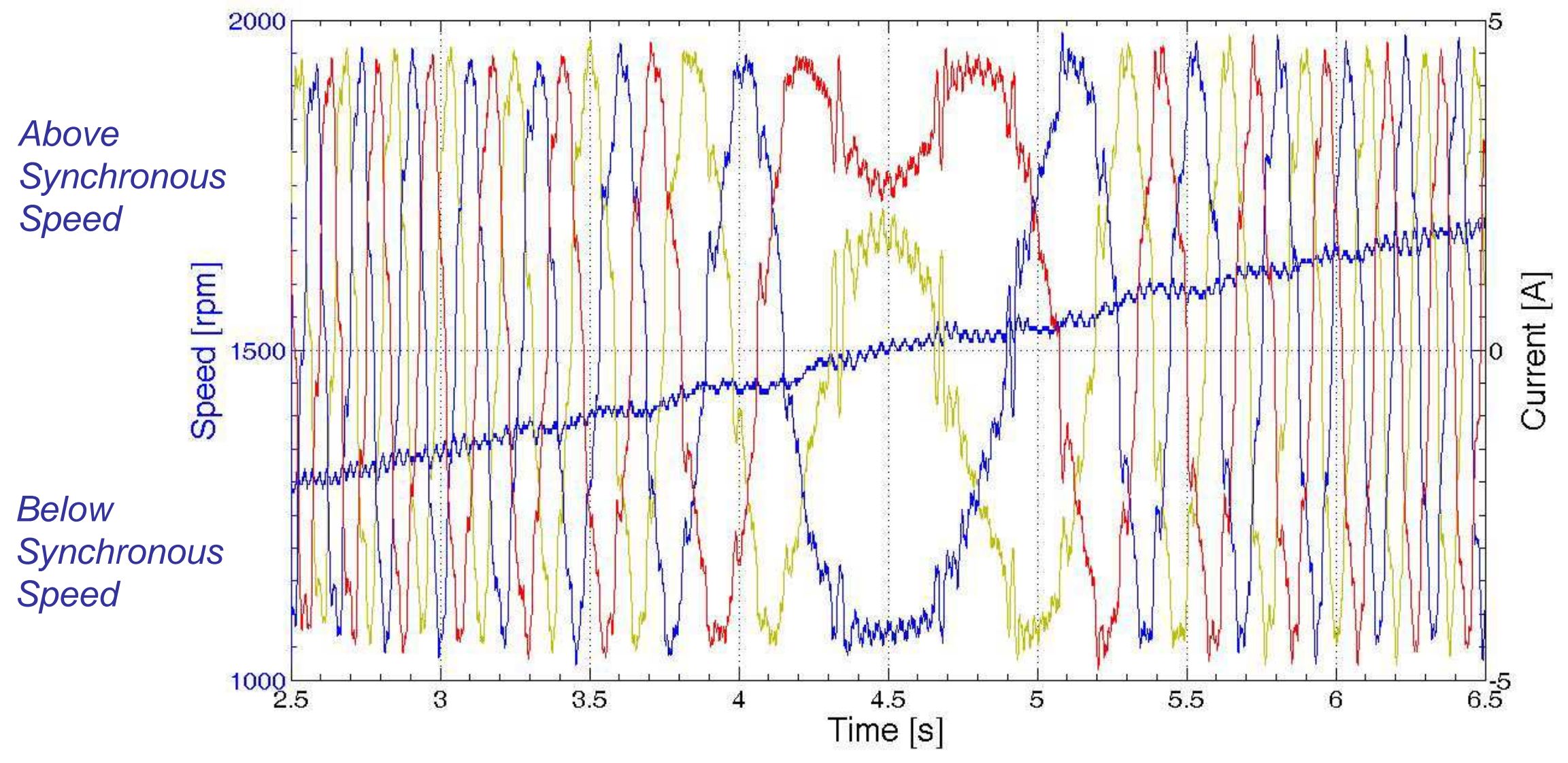




\section{Variable Speed Operation}

IEPC

UNIVERSITY

OF MALTA

Rotor Power Reversal During DFIM Speed Transition Through Synchronous Speed

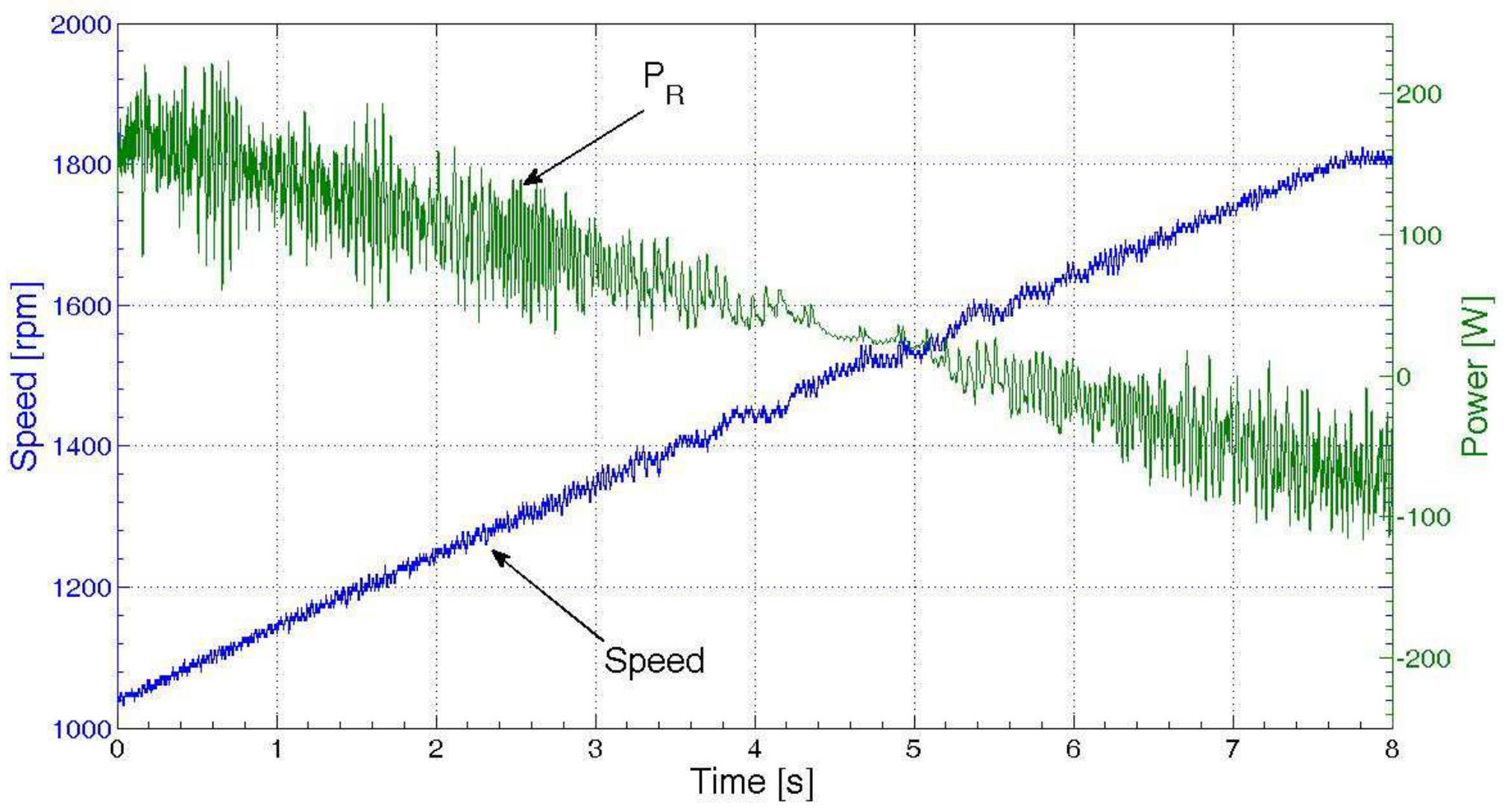




\section{Power Factor Control}

Stator Reactive Power reduced to zero by step in Ird (maintaining constant Stator Flux)

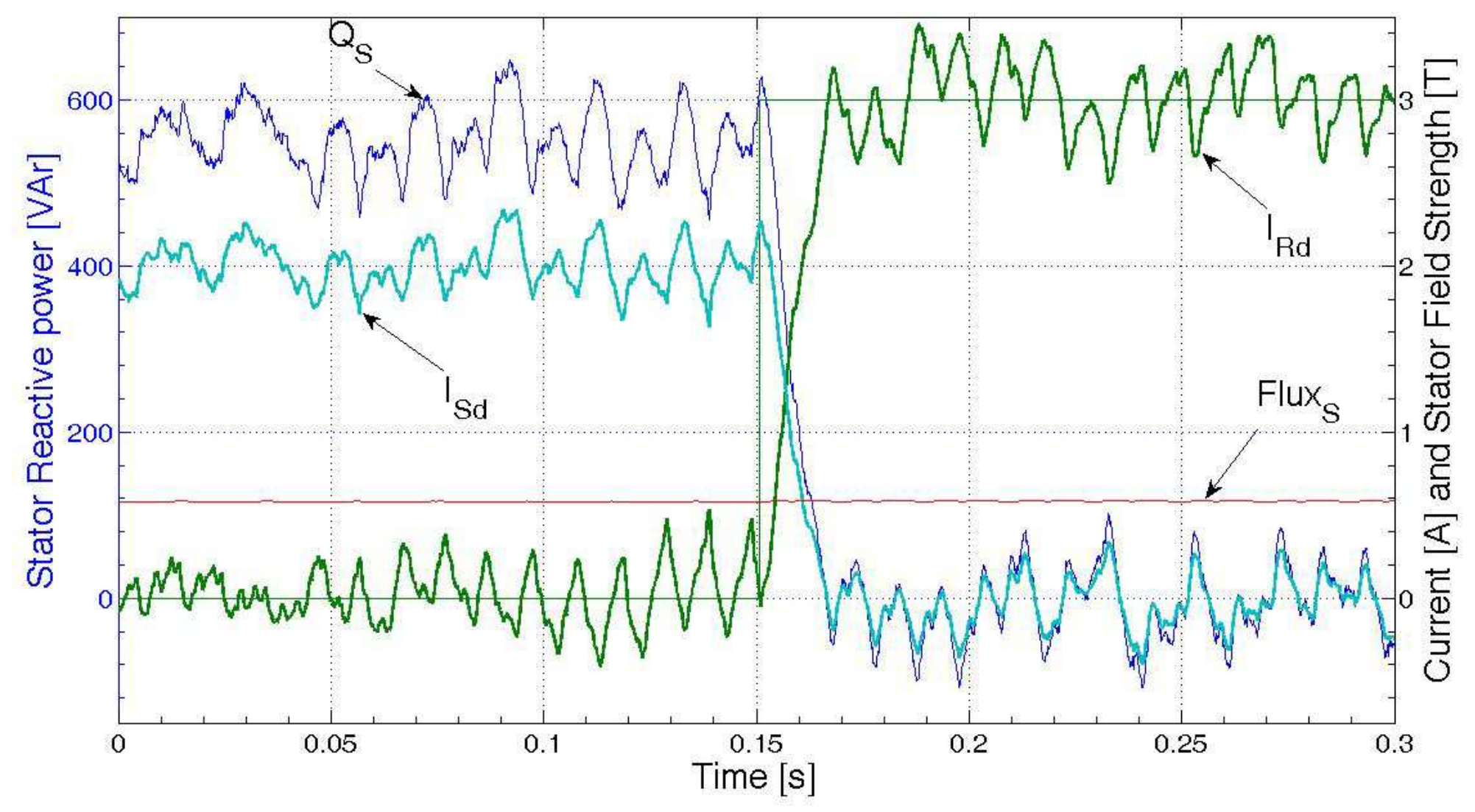




\section{Power Factor Control \\ IEPC}

UNIVERSITY

OF MALTA

Stator Voltage \& Current and Rotor Current

for a step reduction of Stator Reactive Power to zero

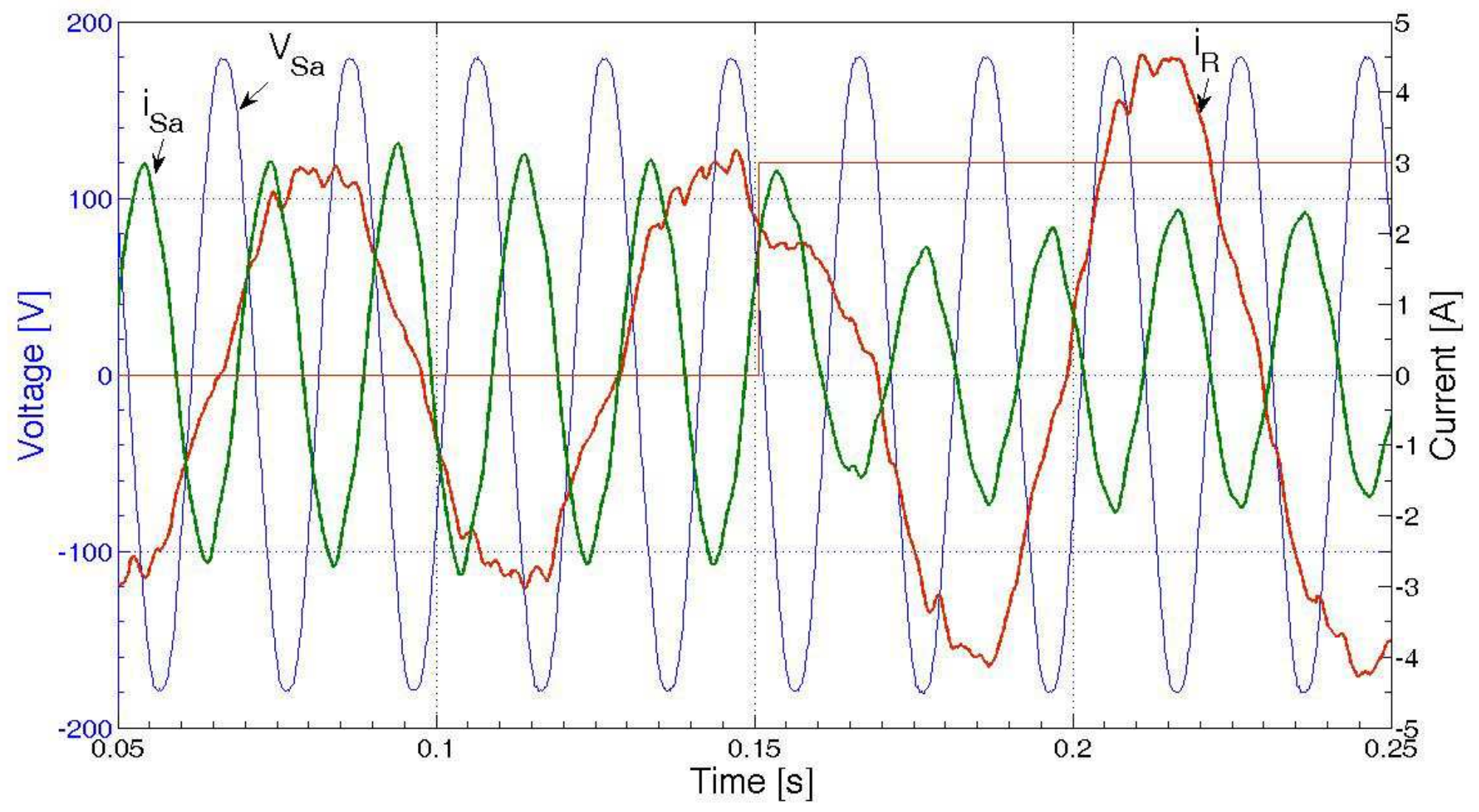




\section{Conclusions}

- Application of matrix converter drive applied to DFIM stator power control for a Wind Energy System

- Matrix Converter used to control rotor circuit of DFIM using SFO vector control

- Results demonstrate control of stator power to grid during tests whilst speed is controlled by dc drive acting as prime mover 